\title{
Assesment of Coronary Artery Disease by The Detection of Inflammatory Marker Like Erythrocyte Sedimentation Rate, Neutrophil Lymphocyte Ratio and Leucocyte Count
}

\author{
MOHAMMAD MONZURULALAM BHUIYAN ${ }^{1}$, MD. SAIFUL ISLAM ${ }^{2}$, SHEULI FERDOUSI ${ }^{2}$, MOUSUMI GHOSH ${ }^{3}$, \\ DEBATOSH PAUL ${ }^{2}$, TUHIN SULTANA ${ }^{2}$, HARISUL HOQUE ${ }^{4}$, QUDDUSUR RAHMAN ${ }^{2}$, A N NASHIMUDDIN AHMED ${ }^{2}$ \\ ${ }^{1}$ Department of Clinical Pathology, Dhaka Medical College Hospital (DMCH), Dhaka, ${ }^{2}$ Department of Clinical Pathology, \\ Bangabandhu Sheikh Mujib Medical University (BSMMU), Dhaka, ${ }^{3}$ Department of Pathology, Monno Medical College and \\ Hospital, Manikgong, ${ }^{4}$ Department of Cardiology, Bangabandhu Sheikh Mujib Medical University, Dhaka
}

Address for Correspondence: Dr Mohammad Monzurul Alam Bhuiyan, Clinical Pathologist, Department of Clinical Pathology, Dhaka Medical College Hospital, Dhaka. E-mail: drmonzucmc@gmail.com

\begin{abstract}
:
Background: The inflammatory marker like erythrocyte sedimentation rate (ESR), neutrophil lymphocyte ratio (NLR), total leucocyte count can be a useful tool to detect and measure the early detection of coronary artery disease (CAD). Objective: To assess the ESR, NLR and total leucocyte count as a useful inflammatory marker for detection of coronary artery disease (CAD). Methods: This case control study was conducted in the Department of Clinical pathology in collaboration with Department of Cardiology, Bangabandhu Sheikh Mujib Medical University (BSMMU), Shahbag, Dhaka from March 2014 to February 2015. Total 134 patients were enrolled in this study who were waiting for further percutaneous coronary intervention (PCI) in the Department of Cardiology, BSMMU; 84 cases were considered as Group I (Patients with CAD) and 50 controls were Group II (Patients without CAD). Coronary artery disease with 50\% coronary artery stenosis and more critical lesion that were diagnosed by percutaneous coronary intervention (PCI) were included in this study as cases. Coronary artery disease with less than 50\% coronary artery stenosis who were diagnosed by percutaneous coronary intervention (PCI) were included in this study as control. The statistical analysis was done by Chi-square test and unpaired sample' $t$ ' test. Results: NLR and ESR was higher in CAD (+) group compared to group without CAD (-) (2.76 ( \pm 0.74$)$ vs. $1.56( \pm 0.15), p<0.001)$ and $(31.07 \pm(18.25)$ vs. 11.76 \pm (6.20), p<0.001).Conclusion: ESR and NLR was higher in patients with angiographically proven CAD compared to those without CAD. ESR and NLR may be a useful inflammatory marker to detect the presence of CAD.
\end{abstract}

Key words: Nutrophil lymphocyte ratio, Coronary artery disease.

Introduction:

The relationship between various inflammatory markers and coronary artery disease (CAD) has been established. ${ }^{1}$ Among these markers, the levels of white blood cell (WBC) subtypes confirmed inflammatory markers that play a crucial role in the pathogenesis of atherogenesis and atherothrombosis, have received significant attention. ${ }^{2}$ It has been established that the WBC count and levels of WBC subtypes not only play an important role in the development of CAD, but can also be used to predict the clinical outcomes of patients with CAD. ${ }^{3}$ Neutrophil lymphocyte ratio (NLR) and erythrocyte sedimentation rate (ESR) is the sign of balance between neutrophil lymphocyte levels in the body and an indicator of systemic inflammation. ${ }^{4}$ NLR and ESR is a new indicator for cardiovascular risk and mortality and by which we can predict the risk of coronary artery disease. ${ }^{5}$

Recently, neutrophil lymphocyte ratio (NLR), erythrocyte sedimentation rate (ESR) and leucocyte count is coming forward as an index of severity of coronary artery disease (CAD). ${ }^{6,7}$ ESR, NLR and leucocyte count is a new predictor for cardiovascular risk and mortality. ${ }^{5}$ Interestingly, a study indicated that the leukocyte count was qualified to predict myocardial infarct size whereas 
CRP was not in patients with ST-segment elevated myocardial infarction. This study is also indicated for these patients treated with primary percutaneous coronary intervention. ${ }^{8}$ Based on these studies, high leukocyte and its subsets counts, even within the normal range, appeared to be not only linked to systemic inflammatory response but also to increased risk of cardiovascular disease and adverse prognosis. Moreover, there is no robust consensus in the clinical practice on the leukocyte range association with CAD. 7,9 This may be due to a wide range of frequency in subjects at high risk, to the investigated population or to unknown confounding factors. ${ }^{8}$ Therefore, there is still a need to investigate the association between the frequency of leukocyte subsets and CAD, in subjects with a different disease status.

Several markers of inflammation and of atherosclerosis have been shown to be predictors of CAD. ${ }^{10}$ Multiple inflammatory markers have been evaluated as potential risk factors for the development of CAD and its complication. The inflammatory markers which predict CAD events include C-reactive protein (CRP), interleukin-1 (IL1), interleukin-6 (IL-6), fibrinogen and tumor necrosis factor- \pm (TNF- \pm ). ${ }^{11,12}$ The markers of atherosclerosis include ankle arm index (AAI) and aortic pulse wave velocity (aPWV), a marker of arterial stiffness. Combination of measures of inflammation and atherosclerosis might be useful for identification of very high risk in adults. IL-6 might be a better risk discriminator of CAD than CRP in older adults. ${ }^{12}$ But these markers are costly and not available at all places as neutrophil lymphocyte ratio (NLR), erythrocyte sedimentation rate (ESR) and total leucocyte count. Recently, the total leukocyte count, elevated ESR and elevated NLR has been the subject of interest in predicting the risk for future cardiovascular events. An elevated NLR and ESR independently indicate an increased long term risk of mortality in patients with stable CAD. ${ }^{13,14}$ In this study, we aimed to investigate relationship between ESR, NLR and leucocyte count with CAD proven with angiography and to establish ESR, NLR and leucocytes count as a useful inflammatory marker in detection of CAD.

\section{Methods:}

This case control study was conducted at the Department of Clinical pathology with the Department of Cardiology, Bangabandhu Sheikh Mujib Medical University (BSMMU), Shahbag, Dhaka from March 2014 to February 2015. 134 patients were enrolled in this study; 84 cases were considered as Group I (Patients with CAD) and 50 controls were Group II (Patients without CAD). Patients with coronary artery disease who have e” 50\% stenosis, adults (18 years and above) patients, patients of both sexes were included in this study. Recurrent myocardial infarction, patients with congenital cardiac disease as shunt or vascular anomalies, pulmonary hypertension (both primary or secondary), acute or chronic infectious diseases, uncontrolled hypertension, known case of patients with cerebrovascular diseases, patients with documented malignancy, hematological disorders, patients with hepatic and renal impairment were excluded from the study. In this study, $2 \mathrm{ml}$ of blood was collected in EDTA tube from the patients prior to PCI for complete blood count (CBC) were measured by haematology autoanalyzer (SYSMEX 4000i), rechecked manually and NLR was calculated in the Department of Clinical Pathology, BSMMU.

After selection, all the patients were thoroughly informed about the aims, objectives and procedure of the study and were encouraged for their voluntary participation. Then an informed written consent was taken from each subject. A detail personal, medical, occupational, educational and smoking history were recorded in a preformed data schedule and thorough physical examinations were done and documented. Tests done in Dept. of Clinical Pathology: CBC with PBF including total and differential count of WBC, erythrocyte sedimentation rate (ESR) and neutrophil lymphocyte ratio (NLR).

\section{Results:}

A total 134 patients were included in the study. 84 cases were considered as Group I (patients with CAD) and 50 controls were Group II (patients without CAD).

The mean age of the patients with CAD (Group I) was $54.73 \pm 8.94$ years, the mean age of the patients without CAD (Group II) was $53.10 \pm 9.47$ years.

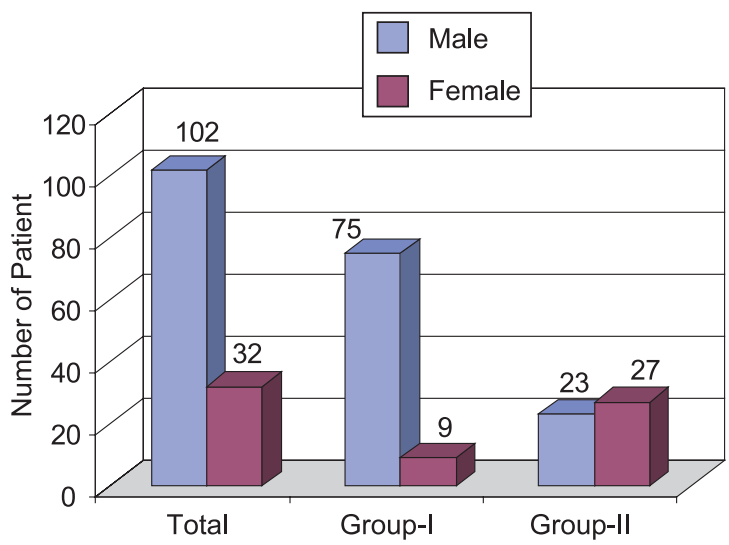

*Chi-square test was done to measure level of significance ( $p$ $<0.001$ ).

Figure 1: Sex distribution of the study population ( $n=134)$. 
Table-I

Association between Group-I and Group-II with mean total WBC count and ESR (n=134).

\begin{tabular}{lccc}
\hline & Group-IMean \pm SD & Group-IIMean \pm SD & P value* \\
\hline TC of WBC $\left(10^{9} / \mathrm{L}\right)$ & $9.90 \pm(1.91)$ & $8.66 \pm(1.37)$ & $<0.001$ \\
Range (min-max) & $5-13.50$ & $6-13.0$ & $<0.001$ \\
ESR(mm/1 $1^{\text {st }}$ hour) & $31.07 \pm(18.25)$ & $11.76 \pm(6.20)$ & \\
Range (min-max) & $5-120$ & $3-28.0$ & \\
\hline
\end{tabular}

* Unpaired sample t test was done to measure level of significance.

Table-II

Distribution of mean NLR with sex $(n=134)$.

\begin{tabular}{lccc}
\hline & \multicolumn{2}{c}{ Sex } & \\
\cline { 2 - 4 } & MaleMean \pm SD & FemaleMean \pm SD & 0.008 \\
\hline NLR & $2.44( \pm 0.82)$ & $1.92( \pm 0.76)$ & $1.25-5.0$ \\
Range (min-max) & $1.23-7.0$ & & \\
\hline
\end{tabular}

* Unpaired sample t test was done to measure level of significance.

Table-III

Mean NLR difference between Group-I and Group-II ( $n=134)$.

\begin{tabular}{lccc}
\hline & Group-I & Group-II & $P$ value* \\
& Mean \pm SD & Mean \pm SD & $<0.001$ \\
\hline NLR (Ratio) & $2.76( \pm 0.74)$ & $1.56( \pm 0.15)$ & \\
Range (min-max) & $2.0-7.0$ & $1.23-1.74$ & \\
\hline
\end{tabular}

* Unpaired sample $\mathrm{t}$ test was done to measure level of significance.

Cut off value of NLR was 1.74.

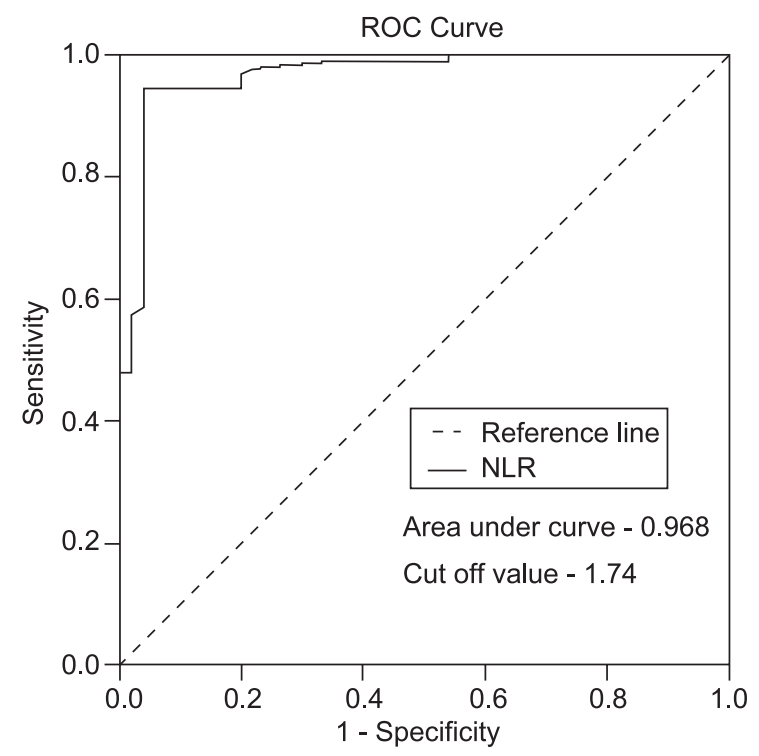

Diagonal segments are produced by ties

Fig.-2: Determination of sensitivity and specificity of neutrophil lymphocyte ratio (NLR) and Group-I (patients with $C A D)$ by ROC curve:
The test result variable(s): NLR (Ratio) (0.968) has at least one tie between the positive actual state group and the negative actual state group, 95\% Confidence Interval of the difference lower 0.939 and upper 0.997. Then cut off value was 1.74 .

\section{Table-IV}

Receiver-operator characteristic (ROC) curve of neutrophil lymphocyte ratio and Group-I (patients with $C A D)$ for prediction of coronary artery disease $(C A D)$.

\begin{tabular}{|c|c|c|c|c|c|c|}
\hline & \multirow{2}{*}{$\begin{array}{c}\text { Cut } \\
\text { of } \\
\text { value }\end{array}$} & \multirow[t]{2}{*}{$\begin{array}{l}\text { Sensi- } \\
\text { tivity }\end{array}$} & \multirow[t]{2}{*}{$\begin{array}{l}\text { Speci- } \\
\text { ficity }\end{array}$} & \multirow{2}{*}{$\begin{array}{c}\text { Area } \\
\text { under } \\
\text { the } \\
\text { ROC } \\
\text { curve }\end{array}$} & \multicolumn{2}{|c|}{$\begin{array}{c}\text { 95\% Confidence } \\
\text { interval (CI) }\end{array}$} \\
\hline & & & & & $\begin{array}{l}\text { Lower } \\
\text { bound }\end{array}$ & $\begin{array}{l}\text { Upper } \\
\text { bound }\end{array}$ \\
\hline $\begin{array}{l}\text { Neutrophil } \\
\text { lymphocyte } \\
\text { ratio (NLR) }\end{array}$ & 1.74 & $98 \%$ & $58 \%$ & 0.968 & 0.939 & 0.997 \\
\hline
\end{tabular}

\section{Discussion:}

Erythrocyte sedimentation rate (ESR), neutrophil lymphocyte ratio (NLR) is the sign of balance between neutrophil and lymphocyte levels in the body and an 
indicator of systemic inflammation. ${ }^{15}$ ESR, NLR is a new predictor for cardiovascular risk and mortality. ESR, NLR and leucocyte count could play an important role in early detection of atherosclerosis and by which we can initiate early treatment. ${ }^{6}$

Coronary artery disease occurs at any adult age, but it is the disease of middle and old age. In our study, the mean age of the patients in Group I (patients with CAD) was $54.73( \pm 8.94)$ years as compared to $56.59 \pm 13.63$ years and $58.01 \pm 12.9$ years, studies done by Assiri AS et al., (2012) and Al-Saif SM et al., (2011). ${ }^{16,17}$ It was 52.0 \pm 8.6 years in a study reported by Siddique MA et al., (2010) and 56.6 years by Ullah M et al., (2011) in Bangladesh. ${ }^{18,19}$

There was clear male predominance in Group I (89.28\%). In Group II there was $46 \%$ male. The difference was statistically significant between the groups $(\mathrm{p}<0.001)$. Our study is consistent with findings of study done by Bittencourt C et al., (2014). ${ }^{20}$ They also found male predominance. They found that in patients with CAD group, male patient was $61.2 \%$ and in the other group male patient was $40 \%$. There was also statistically significant association between the groups ( $\mathrm{p}<0.001$ ). Our findings are also similar with the results found in the study conducted by Sonmez O et al., (2013), Sayeed MA et al., (2010), Paudel R et al., (2009), Joshi P, (2007). 5,21,22,23

In this study, we found a relation of ESR, NLR with the presence of coronary artery disease. There is no doubt in cardiovascular medical science that atherosclerosis is a chronic inflammatory disease. ${ }^{24,25}$ In our study mean

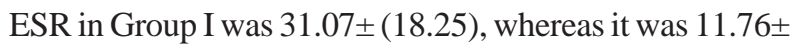
(6.20) in Group II. There was statistically significant association between two groups in this regards $(\mathrm{p}<0.001)$. Our findings are similar to a study conducted by Sahin $S$ et al., (2013). ${ }^{4}$ They also found higher mean ESR in patients with CAD group (5-120 vs 3-28.0) $(\mathrm{p}<0.001)$.

Our study mean total count of WBC in Group I was $9.90 \pm$ (1.91), whereas it was $8.66 \pm$ (1.37) in Group II. There was statistically significant association between two groups in this regards ( $\mathrm{p}<0.001)$. We found higher total WBC count in CAD positive group (Group I) than CAD negative group (Group II). Sonmez O et al., (2013) also found higher total count WBC in patients with coronary artery disease $(\mathrm{p}<0.001)^{5}$

In our study mean NLR in Group I was 2.76 ( \pm 0.74$)$, whereas it was $1.56( \pm 0.15)$ in Group II. There was statistically significant association between two groups in this regards ( $\mathrm{p}<0.001$ ). Our findings are similar to a study conducted by Sahin S et al., (2013). ${ }^{4}$ They also found higher mean
NLR in patients with CAD group (1.98 \pm 0.85 vs $2.69 \pm 1.74)$ $(\mathrm{p}<0.001)$. Sonmez O et al., (2013) also found higher mean NLR in patients with coronary artery disease (2.3 vs 1.6 ) $(\mathrm{p}<0.001)^{5}$

ESR, NLR can be a useful tool to detect and measure the future prognosis of CAD. In this study, we found a relationship between ESR, NLR and CAD proven with angiography and ESR, NLR as a useful inflammatory marker in detection of CAD.

\section{Limitation:}

The main limitation of our study was the small sample size and this was a non-randomized single center study. Patients with exclusion criteria were excluded on the basis of clinical feature. No confirmatory pathological tests were carried out to exclude these patients because of financial resource and time constraint.

\section{Conclusion:}

Increased erythrocyte sedimentation rate (ESR) and neutrophil lymphocyte ratio (NLR) is a risk factor for developing coronary thrombosis leading to coronary artery disease (CAD). With the help of ESR, NLR we can take preventive measure and precaution to reduce the risk of coronary artery disease. ESR, NLR is a simple, cost effective, readily available test to predict the risk of CAD and can take extra measure and preventive intervention to prevent CAD.

\section{Acknowledgement:}

Authors of this study are thankful to the authority of the Department of Cardiology, BSMMU and the Department of Clinical Pathology, BSMMU, for their nice cooperation during sample collection, laboratory procedure and also thankful to the study subjects for their active and enthusiastic participation.

\section{References:}

1. Ate ${ }^{\circ} \mathrm{AH}$, Canpolat U, Yorgun H, Kaya EB, Sunman H, Demiri E, Taher A, Hazirolan T, Aytemir K, Tokgözoglu L, Kabakçi G, Oto A: Total white blood cell count is associated with the presence, severity and extent of coronary atherosclerosis detected by dual source multislice computed tomographic coronary angiography. Cardiol J 2011; 18:371-77.

2. Horne BD, Anderson JL, John JM, Weaver A, Bair TL, Jensen KR, Intermountain Heart Collaborative Study Group. Which white blood cell subtypes predict increased cardiovascular risk? J Am Coll Cardiol 2005; 45: 1638-43.

3. Madjid M, Awan I, Willerson JT, Casscells SW, Leukocyte count and coronary heart disease: implications for risk assessment. J Am Coll Cardiol, 2004; 44:1945-56. 
4. Sahin S, Sarikaya S, Akyol L, Altunkas F, Karaman K, Evaluation of neutrophil to lymphocyte ratio as an indicator of presence of coronary artery disease in diabetic patients, National journal of medical research, 2013; 3(4): 300.

5. Sönmez O, Erta ${ }^{\circ}$ g, Bacaksýz A, Tasal A, Erdoðan E, Asoðlu E, Uyarel H, Göktekin O, "Relation of neutrophil -tolymphocyte ratio with the presence and complexity of coronary artery disease: an observational study ,"Anadolu Kardiyol Derg, 2013; 13: 662-7.

6. Shen XH, Chen Q, Shi Y, and Li H W, “Association of Neutrophil/Lymphocyte Ratio with Long-Term Mortality after St Elevation Myocardial Infarction Treated with Primary Percutaneous Coronary Intervention,” Chin Med J, 2010; 123(23): 3438-43.

7. Tamhane UU, Aneja S, Montgomery D, Rogers EK, Eagle KA, and Gurm HS. "Association between Admission Neutrophil to Lymphocyte Ratio and Outcomes in Patients with Acute Coronary Syndrome,” Am J Cardiol, 2008; 102, 653-7.

8. Rasouli M, Nesarhosseini V, Kiasari AM, Arab S, Shariati R, et al. The multiplicative interactions of leukocyte counts with some other risk factors enhance the prognostic value for coronary artery disease. Cardiol J 2011; 18: 246-253.

9. Papa A, Emdin M, Passino C, Michelassi C, Battaglia D, et al. Predictive value of elevated neutrophil-lymphocyte ratio on cardiac mortality in patients with stable coronary artery disease. Clin Chim Acta 2008; 395: 27-31.

10. Ridker PM, Hennekens CH, Buring JE, et al. C-reactive protein and other markers of inflammation in the prediction of cardiovascular disease in women. N Engl J Med. 2000; 342: 836-43

11. Zairis MN, Adamopoulou EN, Manousakis SJ, Lyras AG, Bibis GP, et al. The impact of hs C-reactive protein and other inflammatory biomarkers on long-term cardiovascular mortality in patients with acute coronary syndromes. Atherosclerosis 2007; 194: 397-402.

12. Rodondi N, Locatelli I, Aujesky D, Butler J, Vittinghoff E, Simonsick E et al,"Framingham Risk Score and Alternatives for Prediction of Coronary Heart Disease in Older Adults," PLoS One. 2012; 7(3): e34287.

13. Papa A, Emdin M, Passino C, Michelassi C, Battaglia D, et al. Predictivevalue of elevated neutrophil-lymphocyte ratio on cardiac mortality in patients with stable coronary artery disease. Clin Chim Acta 2008; 395: 27-31.

14. Nunez $\mathrm{J}$ et al. Usefulness of the neutrophil to lymphocyte ratio in predicting long-term mortality in ST segment elevation myocardial infarction. American Journal of Cardiology, 2008; 101, 747-52.
15. Zahorec R, "Ratio of Neutrophil to Lymphocyte CountsRapidand Simple Parameter of Systemic Inflammation and Stress inCritically ill,” BratislLekListy, 2001; 102(1): 5-14.

16. Assiri AS, Jamil AM, Mahfouz AA, Mahmoud ZS, Ghallab M, "Diagnostic importance of platelet parameters in patients with acute coronary syndrome admitted to a tertiary care hospital in southwest region, Saudi Arabia”, J Saudi Heart Association, 2012; 24 (1): 17-21.

17. Al-Saif SM, Al-Habib KF, Ullah A, Hersi A, Al-Faleh H, Alnemer K, Tarabin A, Abuosa A, Kashour T, Al-Murayeh M, “Age and its relationship to acute coronary syndromes in the Saudi Project for Assessment of Coronary Events (SPACE) registry: The SPACE age study”, J Saudi Heart Association, 2012; 24: $9-16$.

18. Siddique MA, PrakashShrestha M, Salman M, Haque KMHSS, Ahmed MK, Sultan MAU, Hoque MH, Zaman SMM, “AgeRelated Differences of Risk Profile and Angiographic Findings in Patients with Coronary Heart Disease”, BSMMU J, 2010; 3(1): 13-17.

19. Ullah M, Sayami LA, Khan MR, Jahan A, Rahman Z, Rahman MT, Majumder AAS, “In Hospital Outcome of Myocardial Infarcton in nondiabetic patients with high on admission blood glucose level”, Cardiovasc. J, 2011; 3(2): 143-48.

20. Célia Bittencourt, Valdecira M Piveta, Carolina SV Oliveira, Felipe Crispim, Deyse Meira,Pedro Saddi-Rosa, Fernando MA Giuffrida and André F Reis, Association of classical risk factors and coronary artery disease in type 2 diabetic patients submitted to coronary angiography. Am J Cardiol; 2014; 96: 343-6.

21. Sayeed MA, Mahtab H, Sayeed S, Begum T, Khanam PA, Banu A, "Prevalence and risk factors of coronary heart disease in a rural population of bangladesh”, Ibrahim Med. Coll. J, 2010; 4(2): 37-43.

22. Paudel R, Panta OB, Paudel B, Paudel K, Pathak OK, Alurkar VM. “Acute Coronary Syndrome In Elderly - The Difference Compared With Young In Intensive Care Unit Of A Tertiary Hospital In Western Nepal”, Journal of Clinical and Diagnostic Research, 2009; 3: 1289-96.

23. Joshi P, Islam S, Pais P, Reddy S, Dorairaj P, Kazmi K, RajPandey M, Haque S, Mendis S, Rangarajan S, Yusuf S, "Risk Factors for Early Myocardial Infarction in South Asians Compared With Individuals in Other Countries”,JAMA, 2007; 297(3): 286-94.

24. Ross R, “Atherosclerosis - an Inflammatory Disease,” N Engl J Med 1999; 340(2): 115-26.

25. Libby P, Ridker PM, Maseri A, “Inflammation and atherosclerosis”; Circulation, 2002; 105(9): 1135-43. 